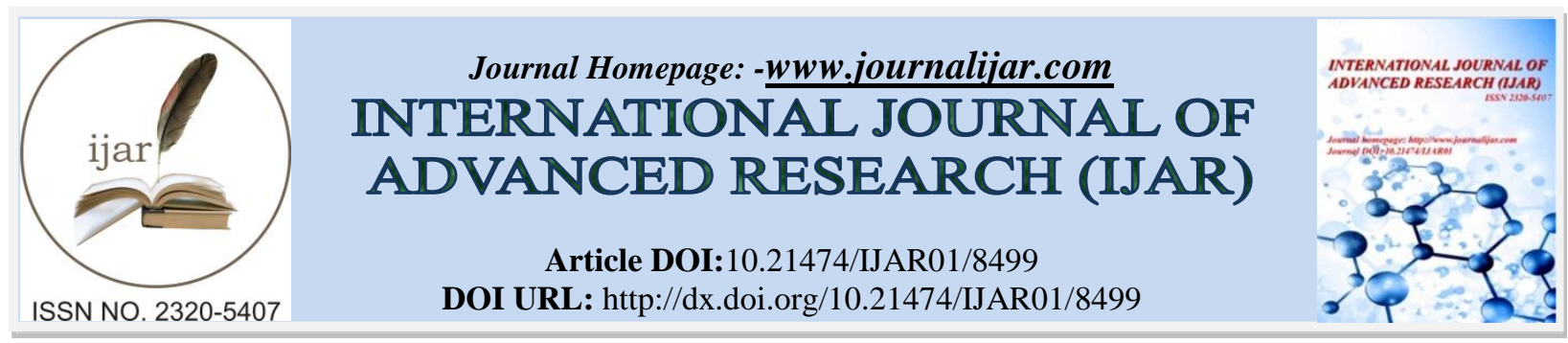

RESEARCH ARTICLE

\title{
A SOCIOLOGICAL STUDY ON AFFECTING FACTORS OF HEALTH AND HEALTH SEEKING BEHAVIOUR.
}

Durlav Pegu.

Research Scholar, Department of Sociology, Dibrugarh University.

\section{Manuscript Info}

Manuscript History

Received: 05 December 2018

Final Accepted: 07 January 2019

Published: February 2019

Key words:-

Behaviour, determinant, factor, health, seeking.

\begin{abstract}
Health is not only determined by the biological factor but also by both cultural and social environment. So the social determinants are a very important factor of health. The social determinants of health are the conditions in which people are "born, grow, live, work, age," and which shape their health status. The main objective of this study was to know the affecting factors and social determinant factors of health seeking behaviour in the study area and to know the people's perception regarding health and disease. The researcher used such as interview schedule (face to face interview technique using semistructured questions), case study. In this study, the researcher has used the survey method for the selection of the respondent. The finding reveals that folk tradition and culture mostly close to the health seeking behaviour of the people. The cultural influence was a major factor of health among the people. Culture shapes the people what to do, where to go for the ill-treatment. Therefore, in the process of health seeking behaviour the people influence from the factor of geography, availability, education, income, poverty, gender disparity, social support and network, their we feelings, interaction, taking of decision, social ties, share of information, emotion, togetherness of activity and integration of this whole activity etc.
\end{abstract}

Copy Right, IJAR, 2019,. ll rights reserved.

\section{Introduction:-}

Health is not only determined by the biological factor but also by both cultural and social environment. The social determinants of health are the conditions in which people are "born, grow, live, work, age," and which shape their health status (Chapman, 2010). There are various factors stands against social determinant of health such as (a) Social environment, (2) Culture, (3) Biology and genetics endowment, (4) Income and social status (5) Employment working conditions (6) Education and health literacy (7) Health service (8) Personal health practices and coping skills, (9) Environment, (10) Social support network (11) Gender, (12) Healthy child development (Asghar et al., 2009). These various factors are effects on people's health and health seeking behaviour. The health seeking behaviour of the individual is closely related to the way how he or she perceives various health problems and what they mean him or her and his or her access to various relevance institutions. In this context, the factors are divided into two terms as an external and internal factor, which are affecting the health seeking behaviour of the individual. The external factors include the level of education, caste, social status, culture, etc. and they can decide the health status of any person including environmental, hospitals, doctors behaviour and their infiltration of technologies etc. 
The internal factors include his/ her inherited health culture, a family background such as occupation, income or poverty, and geography influence to the health seeking behaviour (Nanjunda, 2013; Nanjunda, 2014). There are some other significant factors affects the health and health seeking behaviour of individual such like (1) the type of response of the family member, (2) sources of income, (3) level of education, (4) economical condition of the family, (5) decision makers of the family, (6) severity of illness, (7) cost of treatment, (8) source of information and availability regarding health facilities, (9) types of health facilities, (10) distance of health facilities, (11) ignorance of disease and due to old age such rooted of cultural beliefs of old body ill health, (12) stage of setting sun, (13) lack of knowledge regarding self-care, (14) social structures with rules and norms, (15) gender discrimination, (16) status of women and (17) others factors such as poverty, poor attention of health workers, long process of treatment, deep believe and trust in God for healing during the illness and living alone and lack of someone to take them to the hospital for treatment and feelings of better treatment available elsewhere rather than the formal health institutions (Shaikh and Hatcher, 2004). Therefore, around the health concept of an individual, various socio-cultural factors stand as determinants of his health. So this study is conducted to examine the social determinant factors of health among the people of the study area.

\section{Review of Literature:-}

The health status of the individual in a given community or society largely depend on the health culture prevailing in the community. Health culture includes the people's perception, beliefs, practices of health care and treatment seeking behaviour. A study has been attempted in Bangladesh. Their findings reveal that the socio-economic status of the individual and education play a vital role regarding the health seeking behaviour of the people of the particular research area (Ahamed et al., 2005). This finding is a similar character with the findings of (Uddin and Mazur, 2014). They used a systematic random sample and semi-structured questionnaire to examine the postcyclone health care utilization. Their findings reveal that a household's socio-economic status, as reflected by wealth quintiles, was a major determinant in healthcare utilization. The household heads in the higher wealth quintile were significantly more likely to seek modern allopathic providers for healthcare than those in the poorest quintile.

The affecting factors of health and health seeking behaviour may vary according to their living environment. Due to gender differences, education and literacy level and others factors such like cost, geographical distance and time taken for remoteness also stand as affecting factors of people's health seeking behaviour (Bpsych, 2007). In this context, it is very significant to focus that the service quality, information about this quality, wealth, user fees, and gender are the main determinants of patients' choice among alternative medical treatment (Muriithi, 2013). Therefore, it is seen that type of response of the family members, source of income and economic status of the family, decision makers, severity of illness, cost of treatment, source of information, availability of health facilities, types of health facilities, distance of nearest health facilities, ignorance of disease due to old age (deeply rooted cultural belief e.g. old body ill health, stage of setting sun, lack of knowledge regarding the self care etc), poverty, poor attitudes of health worker, lengthy treatment process, trust on God for healing if ill, living alone and lack of someone to take them to hospitals and feelings of better treatment available elsewhere rather than formal health institutions play a significant role regarding looking, doing, having of their health behaviour (Adhikari and Rijal, 2014). A study conducted in a tribal area of Orissa, India. Their finding reveals that poor socio-economic status and socio-cultural factors play important role in maintaining a high degree of Malaria transmission. They also refer that human behaviour such as the location of hamlets, type of their housing and living, sleeping habits, outdoor activities after dusk, lack of knowledge about disease and treatment seeking behaviour are significant determinants of malaria transmission (Sharma et al., 2001).

The above reviews define the health and health seeking behaviour is influenced in two terms as the biological as well as the socio-cultural term. Socio-cultural factors affect on people's health from the born to die.

\section{Objectives:-}

The main objective of this study is to examine the social determinant factors of health and health seeking behaviour and to know the people's perception regarding health and disease.

\section{Methodology:-}

This is a qualitative study based on both primary and secondary data. The primary data were collected from the field with the help of field visit. To collect the primary data the researcher used such as interview schedule (face to face interview technique using semi-structure questioner), case study. In this study, the researcher has used the survey method for the selection of the respondent. The health concept, affecting factors of health found out as reported by 
the subject or respondent. The researcher purposively selected 100 respondents equally from both villages for this study. The secondary sources were collected from internet sources, journal articles, research papers etc.

\section{Result \& Discussion:-}

If, health is determined by biological as well as socio-cultural factors than health behavior also sees as one type of social behavior which is mainly influenced by the various socio-cultural issues. Understanding a disease/illness is not a medical subject rather it is mainly reliant on the common information of the concerned community (Nanjunda, 2014). Culture is a key determinant factor of health. People's perception and belief are interrelated with the culture. The ritual activities and strong belief on superstations are an indispensable part of the culture. Due to the influence of cultural aspect, the villagers of this research area consider some responsible factors as causes of disease as due to non-regularity of their traditional ritual acts and angry of ancestors, taboos and god. It may be caused by wrong work done by the individual, chanting mantras, seasonal change, and hereditary flows. The tradition and religious aspect as none separated things in their health seeking behaviour.

Geographical location and remoteness is an important factor of health seeking behaviour of this study area which crucially impacts on people's health behaviour. In their study (Rahman et al., 2012) they found that Baiddya, daactor (quack), untrained pharmacist and drug sellers are most familiar practitioners for the villagers. Due to low cost, availability, easy to access and nearest to the health facilities, people desire to go with the nearest practitioner. This is similar findings of our study. The villagers are most preferences with the traditional healer, untrained pharmacy and drug seller, and local daactor. In this study, it is found that due to their availability, easy to access with low cost of money the villagers want to consult them for treatment. They mentioned that in the seasonal flu, fever, any kind of pain quickly recovery by the traditional healing of medicine and offering of some package towards their ancestor. In mild condition, they refer to the traditional method. Modern health facilities are not desirable for them because of the perception of the quality and manner of the treatment and communication are overriding costs for them. The government health center available in the village but it is just in name. The district hospital and private clinic located in the town area and far away from the village. In the field visit with the survey method, it was found that some villagers are suffering from joint pain from two years ago. But they don't want to check up at the hospital due to more distance from the hospital from the located village. Transport and communication facilities are not well. So the people consult to the traditional healer which is treated without any demand for money.

Income, occupation, poverty identify the economic condition of a person which influences the health at a different level. The poverty also another factor of health, due to poverty people faces a lot of problem in health accessibility. The relationship and interaction of both health and income are not easy to reveal yet but in some cases or occasionally the economic condition influence the people in their accessibility of health care service. A households socio-economic status, as reflected by wealth quintiles, is a major determinant of health care utilization. The households who have higher wealth quintiles are significantly more likely to seek modern health practitioner for health treatment rather than those in the poorest quintiles. They free from the effect of sickness upon the food behaviur (Uddin and Mazur, 2014). Health treatment seeking behaviour is may be determined by the source of income, economic status of the family and poverty (Shaikh and Hatcher, 2004). In the field visit, some cases found which is most familiar with the income and economic condition of the people.

"I am a daily wage earner worker and my family depends on my income. But my monthly income is bellow to 5000. So, I could not afford to lose wages and so continued to go for work. But Around one year back, one day suddenly I developed a severe fever with shivering vomiting. So consulted the traditional healer of bhokot or dondai. After performing our traditional ritual practice and the traditional method of healing system I felt well. Again I started to work and able to do 2 days continue. But one weak later felt very serious. The doctor said that my condition is a result of my hard work. After a while, the fever became severe and I also became very weak and unable to do work. Now my family members face lots of economic problems. So, due to the economic compulsion, the treatment also delayed and finally the sickness condition effect to the food behaviour and other aspects of my family" (Household No, 10).

"I am working in the biscuit factory, not interested to go at govt. health facilities or hospital during illness due to my compulsion of the job. If one day I miss attending my job the salary will be deducted. So if I feel uncomforting of my body then consult to the village visit daactor(quack). He visits the village so easily gets him so I am not missing to meet him at night" (Household No, 2). 
Therefore, from the above cases, our finding reveals that the compulsion of the job, daily wage earning the people refers to the traditional healer or village daactor (quack). They don't want to go to the hospital due to their daily work. As such they exclude from a quality health treatment. So the economy is an important determinant of health.

Gender is a socio-cultural concept, a social phenomenon and it is socially constructed. Simply the gender refers to personality traits and behaviour in distinction from the body as male and female. As per the gender differences, the role of males and females are different in nature. Basically, gender is determined by the conception of tasks, functions, and roles attributed to women and men in society, in public and private life (Saikia, 2014). Pegu (2017) attempted a study on gender discrimination against Mising women and mentioned that gender disparity has been seen during the delivery time, taking of their traditional food habits. It is prevailing among the villagers that during the delivery time they practice a duration which is called "Oboyotnam" (the adopting of traditional food items and avoiding some foods). In this time when boy child is born then a male chicken has killed to take the "Jaal”(which is a food item consisting of chicken meat, Jaluk (papper), Pimpoli (jaborandi pepper), Ombita (papaya), Rugji (fern), Marsang (spilanthes acmella) etc.). But if a girl child is born then a female chicken is given to eat. The food item of Jaal is taken with Po:ro Apong (black and chocolate colour of rich bear). Our finding also similar to his finding. When we interviewed the respondent, it was found that the boy child is given more importance than a girl. So the reproduction system is not stopped till not getting of the boy child. It was also found that most of the respondents have born three or four female kids but still, they don't want to stop childbirth because they want at least one boy child for the family so they are continuing their childbirth. Because of what the boy child is considered as a future torch of their family. So the boys mostly prefer by the villagers. The gender difference is not only kept in the boundary of child delivery but also In the name of decision making and expense of money women are dominated under male authority. It is their folk tradition that after the presence of husband why the women. So male are authorized to do. Due to none interest of their husband, the women are not interested to go doctor without the presence of her husband. So in some cases, if women go to the doctor when they have to inform her husband. As such the gender disparity affects on health seeking behaviour knowingly or unknowingly.

Educational level of an individual is also considered as another determinant factor of health. Educational level of an individual has a close link with the health seeking behaviour of the people. Good education provides individuals to get a better position in society and they lead the people, enable to take a good decision for their health (MacInnes and Milburn, 1994). In our study, it is found that literate people are engaging with quality health treatment. Most of the illiterate people don't familiar with the biomedicine. In the taking of the interview, the illiterate villagers mentioned that govt. health institute's providing free medicine may side effect on their health. They also think that the health center stock the tablets whose price is very less and it is not working. So though they take a tablet but don't complete the course. They think that more tablet's taking may be harmful to health. Due to their lack of knowledge, the people take the misperception. But some respondent who are educated and say that health is primary. If health is being well then everything is well. So they always refer the doctor in different ails.

As a major social determinant of health, the social networks and supports play a vital role in the lay consultation of health problem among the villagers in this study area. Social supports not only give material recourses but also they provide love, emotions, and attachments to an individual. They are like social relationships and a ubiquitous part of our life, serving important social, psychological and behavioral functions across the life span. It is a very important aspect for health seeking behaviour of the people and which helps to save a life in risky condition also (Uchino et al., 1996). According to the villagers, it influences the psychological condition of the patients and helps for speedy recovery. Social support helps the sick person to take confidence, mentally strong and satisfied. If all family members are present behind the patients, the patients get mentally support. Social support also extended from friends, relatives, and neighbors to the sick person. They advise the sick person to go to the health practitioner in case of evident delays. When the sick person doesn't recover after a long time then they advise repentance of wrong deeds and non-regularity of their traditional ritual activities or sacrificing activities etc. Such friends, relatives, and neighbors also give advice or suggestion for treatment and provide financial and non-financial support to the patient's family. The social ties, the interaction of the individual and development of their we feelings, day to day cohesion also has been seen with the attached meaning of their social activity of support and networking.

Therefore, the major findings of our study reveal that people seem the causes of disease in a different level. It may be seen that a disease is seen upon the individual due to their non-regularity of traditional ritual acts and angry of ancestors, taboos and god. It may be caused by wrong work done by the individual, chanting mantras, seasonal change, and hereditary flows. Due to these strong beliefs and perceptions according to the villagers, a disease is not 
under control of human being so it should be cured by the power of superstitions which belongs to the traditional healer with their performing of ritual acts. Therefore, the people go to the traditional healer during the illness condition. Geographical location and remoteness of the health care service also another important factor of health seeking behaviour. If the illness is cured under the traditional healer or local medicine man (which is easily getting in the village) why go to the hospital with override cost. When the symptom of illness is seen as severe and needful to take good treatment then have to go to the hospital. The people mostly prefer the traditional healer or local medicine man because of their availability, easy accessibility, enable to take treatment without much expense. Because of what, the economic condition also a significant indicator of health. The gender disparity and different level of education also play role in the people's health seeking behaviour. Importance of boy child and unwanted entity of girl child also impact on health behaviour. The educated people are closing with the high quality of health care service. In this context, the most important factor is the social ties, social interaction among the people which enable to form social support, social network, and social integration. This is helpful for the individual to take information, sharing emotion, involving with the together activity regarding the illness cure. Due to these social ties, interaction, sharing information and emotion, the sick person feeling mentally strong and they able to take a proper decision to take the prevent and cure of illness. Therefore, finally it is saying that, the lay consultation, their we feelings, taking of decision, sharing information, interaction, strong belief system, cultural aspect, availability and accessibility of health facilities and income and educational level of individual, socio-cultural concept of gender disparity also deeply influence the health seeking behaviour of the people.

\section{Conclusion:-}

Health is not a single term. It is a multidimensional aspect. Therefore, it is not only determined by the biological factor but also socio-cultural factors. The social determinants of health are the conditions in which people are "born, grow, live, work, age," and which shape their health status (Chapman, 2010). Individual health is influenced by the various factors at a different level. In the study area, it is found that taking of perception regarding causes of disease, taking any activity in the name of disease preventive and cure, they are influenced by the socio-cultural factors. In this context, cultural influence is the most important one. On the other hand education, income, occupation, gender, folk tradition, social support and network, social ties, interaction, taking of decision, lay consultation, we feelings, sharing information, emotion, involving togetherness regarding illness cure and the geographical location and remoteness of health provider also determine the health condition of the people.

\section{References:-}

1. Adhikari, D., \& Rijal, D. (2014). Factors Affecting Health Seeking Behaviour of Senior Citizens of Dharan. Journal of Nobel Medical College, 3(1), 50-57, (e).

2. Ahmed, S. M., Tomson, G., Petzold, M., \& Kabir, Z. N. (2005). Socio-economic Status Overrides Age and Gender in Determining Health Seeking Behaviour in Rural Bangladesh. Bulletin of the World Health Organization, 83, 109-117, February, (e).

3. Asghar, Z., Attique, N., Urooj, Amena. (2009). Measuring Impact of Education and Socio-economic Factors on Health for Pakistan. The Pakistan Development Review, 48(4Part-II), 653-674, (e).

4. Bsych, T. P. (2007). Utilization of Health and Medical Service: Factors Influencing Health Care Seeking Behaviour and Unmet Health Needs in Rural Areas of Kenya. http://ro.ecu.edu.au/theses/46 (retrieved on 02/ $09 / 2017$ at $1.00 \mathrm{pm})$.

5. Chapman, A. R. (2010). The Social Determinants of Health, Health Equity and Human Rights. Health and Human Rights, 12(2), 17-30, (e).

6. MacInnes, A., \& Milburn, K. (1994). Belief Systems and Social Circumstances Influencing the Health Choices of People in Lochaber. Health Education Journal, 53, 58-72, (e).

7. Murithi, K. M.(2013). The Determinants of Health Seeking Behaviour in Nairobi Slum, Kenya. European Scientific Journal, 9(8), 151- 164, (e).

8. Nanjunda. (2013). Understanding Social Determinants of Health Seeking Behaviours and Medical Pluralism: A Rational Framework for Rural Health Policy and Systems Development. Journal of Media and Social Development, 74-87, (e).

9. Nanjunda. (2014). Factors Affecting Health Seeking Behaviour and Medical Pluralism Among Rural Population: Implications for Health Care Professionals. Sri Ramachandra Journal of Medicine, 7(1), 14-21, (e).

10. Pegu, Durlav. (2017). Gender Discrimination Against Women: A Sociological Study in Two "Mising" Villages of Dhemaji District of Assam. International Journal of Research in Management \& Social Science, 5(3VI), 4753, July-September (e). 
11. Rahman, S. A., Kielmann. T., McPake, B., \& Normand, C. (2012). Health Care-Seeking Behaviour Among the Tribal People of Bangladesh: Can the Current Health System Really Meet Their Needs?. Journal of Health, Population and Nutrition, 30(3), 353-365, (e).

12. Saikia, J. P. (2014). Gender: Themes \& Issues. Ajanta Prakashan, Bazar Sita Ram Delhi, $35-45$, ( $3^{\text {th }}$ edition).

13. Shaikh, B. T. \& Hatchar, J. (2004). Health Seeking Behaviour and Health Service Utilization In Pakistan: Challenging The Policy Makers, Journal of Public Health, 27(1), 49-54, (e).

14. Sharma, S.K., Pradhan, P., \& Padhi, D.M. (2001). Socio-economic Factors Associated With Malaria in a Tribal Area of Orissa, India. Indian Journal of Public Health, 45(3), 93 - 98, (e).

15. Uchino, B. N., Cacioppo, JT., Kiecolt-Glaser, J.K. (1996). The Relationship between Social Support Physiological Processes: A Review with Emphasize on Underlying Mechanisms and Implications For Health. Psychological Bulletin, 119(3), 488-531, (e).

16. Uddin, J. \& Mazur, E. R. (2014). Socio-economic Factors Differentiating Health Care Utilization of Cyclone Survivors in Rural Bangladesh: A Case Study of Cyclone Sidr. Health and Policy Planning, 1-9, (e).

17. Grad, F. P. (2002). The Preamble of the Constitution of the World Health Organization, Bulletin of The World Health Organization, 80(12), 982, (e). 